\section{Shart Oreport}

Department of Anatomy, Government Medical College and Hospital, Chandigarh-60030, India

Correspondence: 09646121529

Email:drmahesh1965@gmail.com

\title{
Pentafurcation of the coeliac trunk
}

\author{
Megha Rapotra, Mahesh Sharma, Amandeep Kaur
}

\begin{abstract}
The coeliac trunk is the first ventral branch of the abdominal aorta. It supplies the supracolic organs. The hepatic artery, splenic and left gastric arteries are considered the main branches of the coeliac trunk. The variations of the branching pattern of the coeliac trunk are important in surgical and radiological procedures. The current study describes an unusual variation in the branching of the coeliac trunk.
\end{abstract}

KEYWORDS: Coeliac trunk, Abdominal aorta, Hepatic artery, Splenic artery, Left Gastric artery

\section{Introduction}

The coeliac artery also, known as the coeliac trunk (CT) or coeliac axis is the first ventral branch of the abdominal aorta, arising just below the aortic hiatus of the diaphragm at the level of T12-L1 vertebral bodies. The stem of the artery is about $1.5-2 \mathrm{~cm}$ in lengthand $6-8 \mathrm{~mm}$ in diameter. The coeliac trunk and its branches supply the derivatives of foregut i.e. stomach, spleen, pancreas, liver and part of the duodenum up to the major duodenal papilla. ${ }^{1}$

The most common branching type of coeliac trunk is trifurcation, described by Haller as "Tripus Halleri”, and is still considered to be the normal appearance of the CT. Thethree main branches are the splenic, the common hepatic and the left gastric arteries. ${ }^{2}$ Although the variations in coeliac trunk are usually asymptomatic, they may become important in patients undergoing liver transplantation, laparoscopic surgery, radiological abdominal interventions and penetrating injuries to the abdomen. Detailed knowledge of normal and variant anatomy of the major unpaired arteries of the abdominal aorta is necessary to carry out successful abdominal operations and to avoid complications. Surgeons must practice caution to avoid the unintentional sectioning of small caliber arteries, as may occur during coeliac artery decompression. ${ }^{3}$

\section{Material and Methods}

During routine dissection of the posterior abdominal wall in a formalin fixed adult female cadaver, an anomalous branching pattern of the coeliac trunk was observed in the Department of Anatomy, Government Medical College and Hospital, Chandigarh, India. Structures surrounding the CT were delineated and its branches were carefully dissected and traced from the origin to theirdestination. The diameter and length of the coeliac trunk and its branches were measured with the help of a vernier caliper.

\section{Observation}

The coeliac trunk arose from left antero-lateral wall of the abdominal aorta at a distance of $13.8 \mathrm{~mm}$ from the aortic hiatus. It travelled forward for about $7.85 \mathrm{~mm}$ and 
terminated into splenic and common hepatic arteries. The left inferior phrenic artery arose as the first collateral branch at a distance of $1.8 \mathrm{~mm}$ from the origin of coeliac trunk. The second collateral arose as a common trunk (hepatogastric trunk) from the dorsal aspect of coeliac trunk at a distance of $4.5 \mathrm{~mm}$ and third collateral i.e. dorsal pancreatico-duodenal artery arose at a distance of $5.9 \mathrm{~mm}$ from the origin of coeliac trunk (Figure 1a,b). The diameter of the coeliac trunk was $6.76 \mathrm{~mm}$.

\section{Hepatosplenic Trunk}

(a) Common Hepatic Artery: It arose from the coeliac trunk, passes upward, forward and to the right along the upper border of head of pancreas. Here it gave the gastroduodenal artery and continued as proper hepatic artery, which later on divided into right and left hepatic arteries and entered into the right and left lobe of the liver respectively. The diameter of common hepatic artery was $5.4 \mathrm{~mm}$.

(b) Splenic Artery: It was tortuous with a diameter of $4.91 \mathrm{~mm}$ and ran to the left side along the superior border of the pancreas up to the hilum of spleen.

\section{Collaterals}

(a) Left inferior phrenic artery: It arose from the lateral side of the CT with a diameter of $2 \mathrm{~mm}$ and travelled upward, laterally and gave multiple superior suprarenal arteries to left suprarenal gland.

(b) Hepatogastric trunk: The hepatogastric trunk arose from the posterior aspect of the coeliac trunk, ran posterior for about $2.85 \mathrm{~mm}$ and gave the left gastric artery and the accessory right hepatic artery as its two terminal branches. Left gastric artery was of $2 \mathrm{~mm}$ in caliber. Itascended upwards and to the left in the fold of lesser omentum to supply the stomach. The right accessory hepatic artery supplied the liver in addition to usual right hepatic artery. The diameter of the artery was $1.5 \mathrm{~mm}$. It was placed posterior to the portal vein, inferior vena cava and before entering into the liver it gave one branch to the right lobe and another to the caudate lobe of the liver (Figure 2).

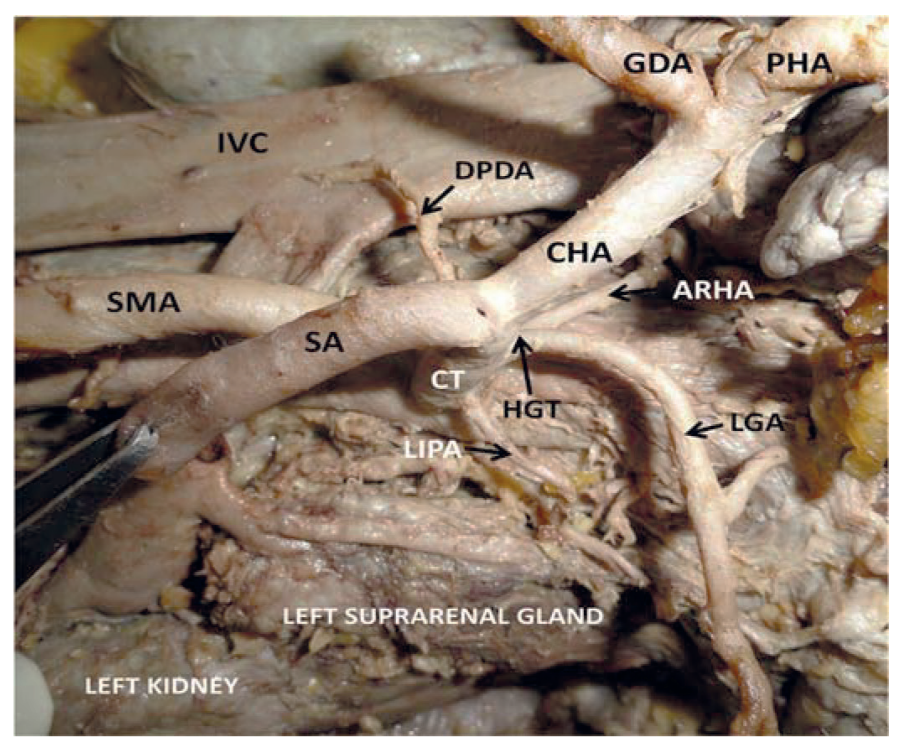

Figure 1 : Dissection of abdomen showing the varient branching pattern of celiac trunk. CT -Celiac Trunk,CHA-Common Hepatic Artery,SA-SplenicTE RY,HGT,ARHA,LGA,LIPA,DPDA,GDA,PHA,SMA IVC
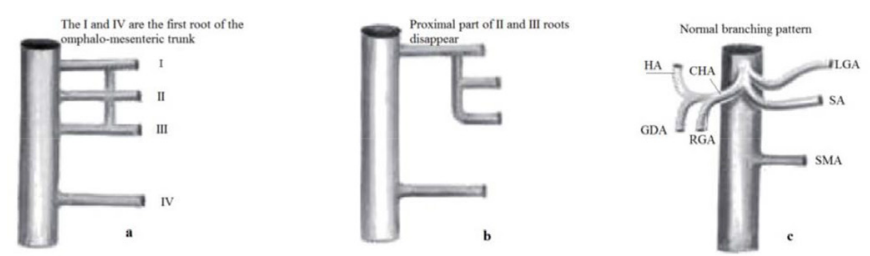

Fig 2 : Diagram showing normal development of the coeliac trunk (a-c) (Source-Kalthur et al)

(c) Dorsal pancreaticoduodenal artery: It arose from the lateral aspect of the coeliac trunk and descended dorsal to the neck of the pancreas to supply the second part of duodenum. The diameter was $1.64 \mathrm{~mm}$.

\section{Embryology}

The anatomical variations in celiac trunk related to its diameter, length or location are thought to have an embryological basis.4Each dorsal aorta before the stage of its fusion gives paired ventral splanchnic branches, which supply yolk sac, the primitive gut and its derivatives. With the fusion of dorsalaortae during the 4th week of intrauterine life, the ventral branches fuse and form a series of unpaired segmental arteries which run in the 
dorsal mesentery of primitive gut. These roots divide into ascending and descending branches to form longitudinal anastomoticchannels. The proximal parts of two central roots disappear and distal parts join with the first root to form the three branches of the celiac trunk and thefourth root forms the superior mesentery artery. Retention or disappearance of parts of this primitive arterial plexus gives rise to numerous anatomical variations in the coeliac trunk. ${ }^{5,6}$ Other factors for the variability of the coeliac axis include the rotation of the midgut, the physiological herniation, the leftward migration of the spleen and the hemodynamic changes in the abdominal viscera. ${ }^{7}$

\section{Discussion}

Origin: In the present case the coeliac trunk arose from the abdominal aorta at the level of L1 vertebra. The findings were comparable to astudy in which the authors concluded that the vertebral level of the celiac trunk ranged from T11-L2. ${ }^{89}$ Similar findings were observed between $\mathrm{T} 12-\mathrm{L} 1$ in $7.68 \%$, upper $1 / 3$ of $\mathrm{L} 1$ in $23.03 \%$ and lower $1 / 3$ of T12 vertebra in 5.12\%.10An another study showed the origin was opposite the L2 vertebra. ${ }^{11}$ Sothe coeliac trunk may be at risk during the treatment for carcinoma of stomach, pancreas and hepatobiliary system due to slight variability of the vertebral level. ${ }^{10}$

Diameter: In literature, the diameter of coeliac trunk has been quoted to range from 9.1-10 mm, 4-10 $\mathrm{mm}, 3-12 \mathrm{~mm}, 10-12 \mathrm{~mm}$, and 6-8 mm. ${ }^{10,12,-15}$ We observed the diameter of coeliac trunk was $6.76 \mathrm{~mm}$ and this was comparable with the Ashalata's finding.

Length:Coeliac trunk is a short trunk ranging from 5-40 $\mathrm{mm}$ in length.12The length of the coeliac trunk was observed to range from 1-2 mm, 1.6-2 mm, 8-40 $\mathrm{mm}, 5 \mathrm{~cm}, 4.2 \mathrm{~cm} .4,10,13,11$, 16Astudy conducted on 20 cadavers showed that in $60 \%$ of cases the length was between $1.3-1.8 \mathrm{~cm}$ and the same range was found in $40 \%$ in another study.17,18The mean length reported in males was $1.24 \mathrm{~cm}$ and 1.01 in females. ${ }^{19}$ In the present study length was found to be $7.85 \mathrm{~mm}$.

Branching Pattern: Variation in the branching pattern of the celiac trunk has beenreported by many authors. The variations vary from classical trifurcation to abnormal trifurcation, bifurcation, quadrifurcation, pentafurcation, hexafurcation, heptafurcation and even absence of the trunk.

In literature, the bifurcation of the coeliac trunk into a hepato-gastric and a hepato-splenic trunkwas reported. The hepatosplenic trunk divided into the common hepatic artery and the splenic artery. ${ }^{20}$ This was similar to our case.

Branches of the coeliac trunk other than its normal branches are called collaterals. ${ }^{11,21-25}$ Reported collaterals include the inferior phrenic artery, the accessory right hepatic artery, the gastroduodenal artery, the dorsalpancreaticoduodenal artery, the left superior suprarenal artery, the left middle suprarenal artery, the middle colic artery, the duodenal artery and the ileal artery. Additional arteries provide collateral circulation which may be important during liver transplant, laparoscopic surgeries and radiological abdominal interventions. ${ }^{23}$

An accessory hepatic artery has been seen to be arising from left gastric artery, which has arising from abdominal aorta. ${ }^{26}$ But in the present case both had a common origin as a small stem from posterior aspect of the celiac trunk. This anomalous branching is rare and it will provide knowledge to gastrointestinal surgeons and to clinicians during diagnostic angiography of liver, gall bladder, stomach and also helps to plan the surgery on these viscera.

The accessory hepatic artery lies in close relationwith the head of pancreas, thefirst part of the duodenum and the portal vein, making it vulnerable to injury during the removal of gall stones from the bile duct.11 Dorsal pancreaticoduodenal artery passes behind the pancreas,so surgeons should take precautions while doing interventional procedures in this area to avoid unnecessary bleeding, ischemia or necrosis of the duodenum. The study of variability of theorigin of the inferior phrenic arteries is of clinical importancewhile performing kidney transplants and suprarenal surgeries. ${ }^{27}$

In conclusion, the knowledge of the variations of the coeliac trunk is useful in surgical and radiological procedures.

\section{References}

1. Standring S. Gray's Anatomy (2005)The Anatomical Basis of Clinical Practice, 39th ed. Philadelphia; Elsevier 
Churchill Livingstone.

2. Haller A (1756) Icones anatomicae in quibus aliquae partes corporis humani delineatae proponuntur et arteriarum potissimum historia continetur.Göttingen: Vandenhoeck.

3. Dandekar UK, Dandekar KN (2014) Variant anatomy of the coeliac trunk-Review of literature with a case report. International Journal of Biomedical And Advance Research,05 (10):480-484

4. Tandler J(1094) Uber dieVarietaten der Arteia coeliaca and deren Entwicklung. Anat Hefte,25: 473-500

5. Datta AK (2005) Essentials of Human Embryology. 5th edn. Kolkata: Current Books International.

6. Kalthur SG, Sarda R, Bankar M (2011) Multiple vascular variations of abdominal vessels in a male cadaver: embryological perspective and clinical importance. J. Morphol. Sci,28(3): 152-156.

7. Reuter SR,Redman HC(1977) Gastrointestinal angiography.2nd Ed.Philadelphia,WB Saunders.pp.31-65

8. Moncada R,Reynes C,Churchill R,Love L (1979) Normal vascular anatomy of the abdomen on computed tomography.Radiol Clin North AM,17(1) :25-37

9. Hofman S, Watson R (1978) Porta hepatis irradiation.Int J Radiat Oncol BiozPhys,(4): 333-336

10. Pant P, Mukhia R, Kumari H, Mukherjee A (2013) Variant anatomy of the celiac trunk and its branches.Global research analysis ,2(6):179-180

11. Nayak SB, Ashwini LS, Swamy Ravindra S, Abhinitha P, Marpalli S, Patil J , Ashwini, Aithal P (2012) Surgically important accessory hepatic artery - a case report. J. Morphol. Sci, 29(3): 187-188.

12. Rio Branco, P.(1912) Anatomia et medicine operatoire $\mathrm{du}$ tronc coeliaque en particulier de l'artere hepatique. Paris,Steinheil, 818

13. Michels NA (1955) Blood supply and anatomy of the upperabdominal organs with descriptive atlas. Philadelphia :Lippincott, USA

14. Pignataro E (1969) L'angiografia selettiva del tronco celiac e dell'arteria masenterica superior.Min.Med,60: 2369-98
15. Ashalatha k (2011) Variations of the Branches of the Coeliac Trunk: a Case Report Asian Journal of Medical Sciences ,2: 148-150

16. Rachana K (2014) Rare variation in arterial branching of celiac trunk with three aberrant hepatic arteries-case report. J.Morphol.Sci, 31(2): 114-117

17. Saeed M, Rufal AA( 2001) Duplication of hepatic artery. Saudi J Gastroenterology, 7(3): 103-108

18. Tiwari S, K. Jeyanthi (2013) Study of coeliac trunk - length and its branching pattern. Journal of Dental and medical Sciences, 8(6): 60-65

19. Petrella S, Rodriguez CF, Sgrott EA, Fernandes GJ, Marques SR, Prates JC. Anatomy and variations of the celiac trunk (2007) Int J. Morphol, 25(2): 249-257

20. Devi sankar K, Bhanu SP,Susan PJ (2011) Variant anatomy of the celiac trunk and its branches.Int J Morphol ,29(2): 581-584

21. Antony D'souza, Vijayalakshmi, Hemalatha, Pugazhandhi, Mamatha H (2012) Anatomical variations in the branches of the coeliac trunk. Journal of Clinical and Diagnostic Research,6(3) (suppl-1): 333-335

22. Pamidi N, Varma S, Vollala V (2008) Anomalous branching pattern of celiac trunk. IJAV, 1: 8-9

23. Mahajan A, Paul S, Das S (2009) An anatomical variation in the branching pattern of celiac trunk. Arch Med Sci,5(1): 117-119.

24. Krishna Chaitanya K, Sharada HR, Suseelamma D (2012) Pentafurcation of the celiac trunk. Anat Physiol, S7: 001

25. Astik RB, Dave UH (2011) Uncommon branching pattern of the celiac trunk: origin of seven branches. International Journal of Anatomical Variations, 4: 83-85

26. Hiatt JR, Gabbay J, Busuttil RW (1994) Surgical anatomy of the hepatic arteries in 1000 cases. Annals of Surgery, 220(1): 50-52

27. Rajesh B,Astik,Urvi H.Dave.Uncommon branching pattern of the coeliac trunk: origin of seven branches.International Journal of Anatomical Variations.4:83-85 